\title{
Posterolateral Debridement and Anterior Reconstruction by Limited Spinal Shortening in Thoracic Spine Infections
}

\section{Mohamed E. Abdel-Wanis*, Moustafa Elsayed, Wael Salama, Mohamed A. Mohamed}

Department of Orthopedics, Faculty of Medicine, Sohag University, Egypt

*Corresponding author: Mohamed E Abdel-Wanis, Mobile: (+20)1002007004, Email: wanis307@yahoo.com

\begin{abstract}
Background: Spinal infection is a very dangerous type of skeletal infection as it may be complicated with spin neurological deficit or spinal deformity, so early diagnosis and treatment is very important.

Purpose: The aim of the current work was to evaluate the result of posterolateral debridement and anterior reconstruction by limited spinal shortening in thoracic spine infections.

Patients and Methods: This retrospective clinical study included a total of 10 patients, 5 men and 5 women with thoracic spinal infection, attending at Sohag University Hospital. This study was conducted between 2003 and 2009. All patients were operated in the prone position through a single posterior midline exposure. Posterior stabilization by transpedicular screw fixation was performed. Medial 3 centimeters of 1 or 2 ribs were excised unilaterally. Anterior circumspinal dissection enables debridement of the lesion and evacuation of any abscess. Then, reconstruction of the anterior column was performed by limited spinal shortening followed by posterior fusion.

Results: Causative organisms were TB in 8 patients, Staph aureus in 1 patient and bacteriologic testing of intraoperative samples did not find germs in 1 patient. Mean follow up was 90.3 months (range; 67- 150 months). No active infection occurred tell the end of follow up. Seven patients got neurological improvement. Two complications were encountered: kyphosis progression and temporary neurological deterioration.

Conclusion: In cases of thoracic spinal infections, single posterolateral exposure is sufficient to debride the infected material, decompress the neural elements, and reconstruct the spine. Limited spinal shortening allows anterior reconstruction without the need for bone grafting.
\end{abstract}

Keywords: Spinal infections, Spondylitis, Pott's disease, Spinal, Shortening, Spine reconstruction.

\section{INTRODUCTION}

While spine infections are rare, they are extremely dangerous and can cause spinal instability, neurologic injury, including paraplegia, and death if not treated properly. Bacterial infection, fungus, or tuberculosis may all cause spine infections. The most common form of vertebral osteomyelitis is pyogenic (bacterial) osteomyelitis, the thoracolumbar spine is the most commonly affected area ${ }^{(1)}$. Spinal infections can be classified by the anatomical location involved: the vertebral column, intervertebral disc space, the spinal canal and adjacent soft tissues ${ }^{(2)}$.

Vertebral osteomyelitis affects an estimated 26,170 to 65,400 people annually. An epidural abscess develops in $5-18 \%$ of patients with contiguous distribution of vertebral osteomyelitis or disc space infection. About $30-70 \%$ of patients with vertebral osteomyelitis have no previous infection. Despite significant improvements in care in recent years, the mortality rate from spinal infection is still estimated to be about $20 \%{ }^{(3)}$.

Risk factors for developing spinal infection include conditions that compromise the immune system, elderly patients, patients with significant medical problems (diabetes, etc), and immunocompromised patients (transplant patients) ${ }^{(3)}$.

Anterior debridement and fusion using bone graft or cage is an accepted way of treatment of spinal infections. This can be achieved either through anterior or posterior or two stage (anterior then posterior) surgery (4-9).
The aim of the current work was to evaluate the result of posterolateral debridement and anterior reconstruction by limited spinal shortening in thoracic spine infections.

\section{PATIENTS AND METHODS}

This retrospective clinical study included a total of 10 patients, 5 men and 5 women with thoracic spinal infection, attending at Sohag University Hospital. This study was conducted between 2003 and 2009.

\section{Ethical approval:}

The study was approved by the Ethics Board of Sohag University. Written informed consent of all the subjects was obtained.

Patients were aged 35 - 71 years with mean age 56.5 years. Frankel grading system was used for patient neurological evaluation. Eight patients had neurological affection; 2 Frankel grad A, 3 Frankel grad B, 2 Frankel grade $\mathrm{C}$ and 1 Frankel grade D. Patient 9 was Frankel grade $\mathrm{E}$ but spastic. All patients received radiological examination in the form of plain radiographs and magnetic resonance imaging (MRI). Local kyphosis angles were measured using the lateral cobb angle ${ }^{(\mathbf{1 0})}$. Local kyphosis angle ranged between $0^{\circ}$ to $40^{\circ}$ and (mean $17.5^{\circ}$ ).

All patients were subjected to laboratory investigations including erythrocytic sedimentation rate (ESR) serum C-reactive protein (CRP) and complete This article is an open access article dicense (http://creativecommons.org/licenses/by/4.0/)
Commons Attribution (CC BY-SA) licenter 
blood picture. Three patients were subjected to Widal test and Malta test. ESR in the first hour ranged between 36 and 121 (mean 60.4). CRP ranged between 4 and 384 (mean 49.6).

Most of patients had more than one indication for surgery. The indications for operative intervention were marked neurologic deficit (3), lack of response or worsening neurologic deficit despite drug therapy (3), severe or progressive kyphosis (7), large abscess (5) and spinal instability (4) ${ }^{(11)}$.

All patients were operated in the prone position through a single posterior midline skin exposure. Posterior stabilization by transpedicular screw fixation was performed for one level above and one level below the affected vertebra in all but 2 patients (patients 7 and 8 ). Full bilateral laminectomy was performed. About 3 centimeters of 1 or 2 ribs excised to give access to the vertebral body (Figure $1 \mathrm{~A}$ ). Blount anterior dissection using the finger and gauze was carried out (Figure 1 B). Spatula-originally developed for posterior total en bloc spondylectomy operation by Tomita ${ }^{(1,12,13)}$ - were inserted anterior to the vertebral. The abscess was evacuated, and the lesion was curetted, and biopsied (Figure $1 \mathrm{C}$ and $\mathrm{D}$ ).

In all cases, reconstruction of the anterior column was performed; by limited spinal shortening (Figure 1 E) ${ }^{(1,2,4,411)}$. Then, posterior fusion is performed. Bone graft used was local graft from the ribs and laminae (Figure $1 \mathrm{~F} \&$ Figures 2 and 3).

Post-operatively, a brace was used during walking or sitting for 1.5 months. Fusion was followed by monthly radiographs.

\section{Statistical testing:}

Table (1): Demographic data of the patients.
Kruskal-Wallis test was used to test the statistical significance between preoperative, post-operative kyphosis and kyphosis at the end of follow up.

\section{RESULTS}

Operative time ranged between 100-190 (mean 135) minutes. Causative organisms were TB in 8 patients, Staph aureus in 1 patient and bacteriologic testing of intraoperative samples did not find germs in 1 patient. Mean follow up was 90.3 months (range; 67150 months). No active infection occurred tell the end of follow up. Seven patients got neurological improvement. At the end of follow up 6 patients were Frankel grade E, 3 grade D and 1 grade B. Two complications were encountered; progression of kyphosis (patient 3, figure 4) and temporary neurological deterioration (patient 10) (Table 1).

Post-operative kyphosis angle ranged between $0^{\circ}$ and $19^{\circ}$ (mean $10.9^{\circ}$ ). At the end of follow up, the kyphosis angle ranged between $0^{\circ}$ to $32^{\circ}$ with a mean kyphosis angle $13.6^{\circ}$. The difference between preoperative and post-operative kyphosis did not reach the statistical significance $(P=0.1269)$. The difference between post-operative kyphosis and kyphosis at end of follow up was not statistically significant $(\mathrm{P}=0.4269)$. Also, there was no statistically significant difference between the pre-operative kyphosis and kyphosis at end of follow up $(\mathrm{P}=0.449)$. For the 8 tuberculosis cases, a four-drug regimen of isoniazid, rifampin, ethambutol, and pyrazinamide is used for 6 months ${ }^{(14)}$. Patient 3 received a post-operative combination antibiotic (Ceftriaxone $1 \mathrm{gm} \mathrm{IV/day} \mathrm{and} \mathrm{ciprofloxacin} 500 \mathrm{mg}$ twice daily) for 6 weeks. Patient 10 received the postoperative antibiotics based on the culture and sensitivity (Ceftraixone $1 \mathrm{gm} \mathrm{IV/} \mathrm{day).}$

\begin{tabular}{|c|c|c|c|c|c|c|c|c|c|c|c|}
\hline NO & Sex & \begin{tabular}{|c|} 
Age \\
years)
\end{tabular} & Level & \begin{tabular}{|l|} 
Causative \\
organism
\end{tabular} & $\begin{array}{l}\text { Preoperative } \\
\text { Frankel } \\
\text { grading }\end{array}$ & $\begin{array}{l}\text { Instrument } \\
\text { ation }\end{array}$ & $\begin{array}{l}\text { Follow up } \\
\text { (months) }\end{array}$ & \begin{tabular}{|l|} 
Postoperative \\
Frankel \\
grading
\end{tabular} & $\begin{array}{l}\text { Preoperativ } \\
\text { kyphosis }\end{array}$ & $\begin{array}{l}\text { Postoperative } \\
\text { kyphosis }\end{array}$ & $\begin{array}{l}\text { Kyphosis } \\
\text { at end } \\
\text { of } \\
\text { follow up }\end{array}$ \\
\hline 1 & Male & 71 & Th8-9 & T.B & $\mathrm{B}$ & Th7-10 & 150 & $E$ & 16 & 14 & 15 \\
\hline 2 & Female & 65 & Th6-8 & T.B & B & Th5-9 & 123 & B & 40 & 14 & 16 \\
\hline 3 & Female & 60 & Th11-12 & o growth & $\mathrm{E}$ & Th10-L1 & 96 & $\mathrm{E}$ & 11 & 15 & 16 \\
\hline 4 & \begin{tabular}{|l|} 
Male \\
\end{tabular} & 71 & Th6-7 & T.B & $\mathrm{C}$ & Th5-8 & 94 & $\mathrm{E}$ & 20 & 19 & 22 \\
\hline 5 & Female & 35 & Th8-9 & T.B & $\mathrm{C}$ & Th7-10 & 80 & $\mathrm{E}$ & 30 & 18 & 21 \\
\hline 6 & Male & 63 & Th8-9 & T.B & A & Th8-10 & 78 & $\mathrm{D}$ & 15 & 4 & 6 \\
\hline 7 & Female & 45 & Th9-12 & T.B & A & $\begin{array}{c}\text { Th9-10 and } \\
\text { Th11-12 }\end{array}$ & 77 & $\mathrm{D}$ & 3 & 3 & 8 \\
\hline 8 & Female & 35 & Th8-9 & T.B & B & Th7-9 & 69 & $\mathrm{D}$ & 18 & 9 & 9 \\
\hline 9 & Male & 50 & Th7-8 & T.B & $\mathrm{E}$ (spastic) & Th6-9 & 69 & $\mathrm{E}$ & 22 & 10 & 11 \\
\hline 10 & Male & 62 & Th7-8 & $\begin{array}{l}\text { Staph. } \\
\text { aureus }\end{array}$ & $\mathrm{D}$ & Th6-9 & 67 & $\mathrm{E}$ & 0 & 0 & 0 \\
\hline
\end{tabular}




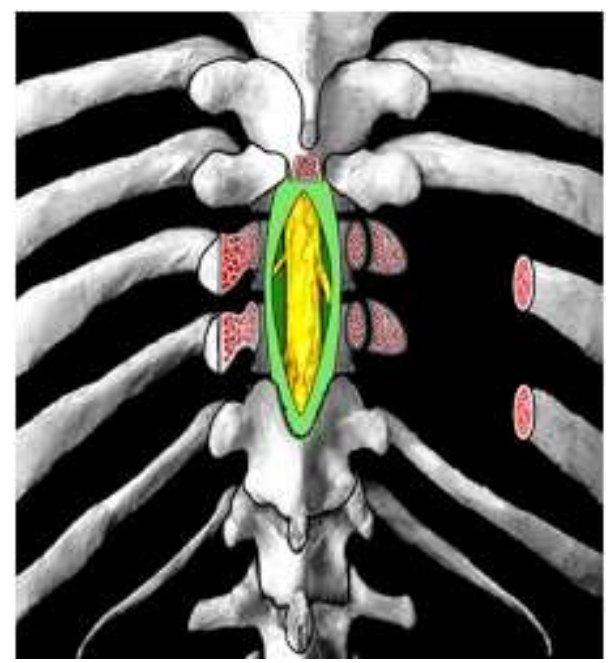

Figure (1 A): Trans-pedicular screws insertion for one level above and one level below the infected level. A rod is inserted in one side. Medial 3 centimeters of one or 2 ribs are excised on the contralateral side to the inserted rod.

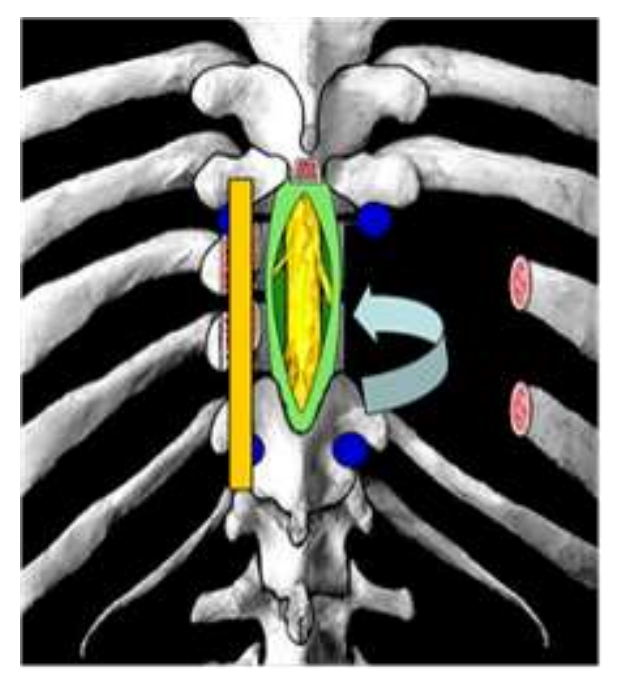

Figure (1 B): Circum- spinal dissection was performed.

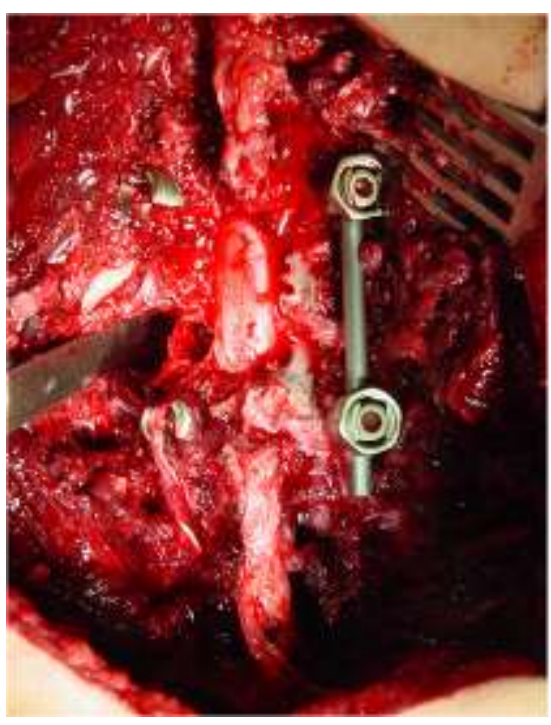

(C)

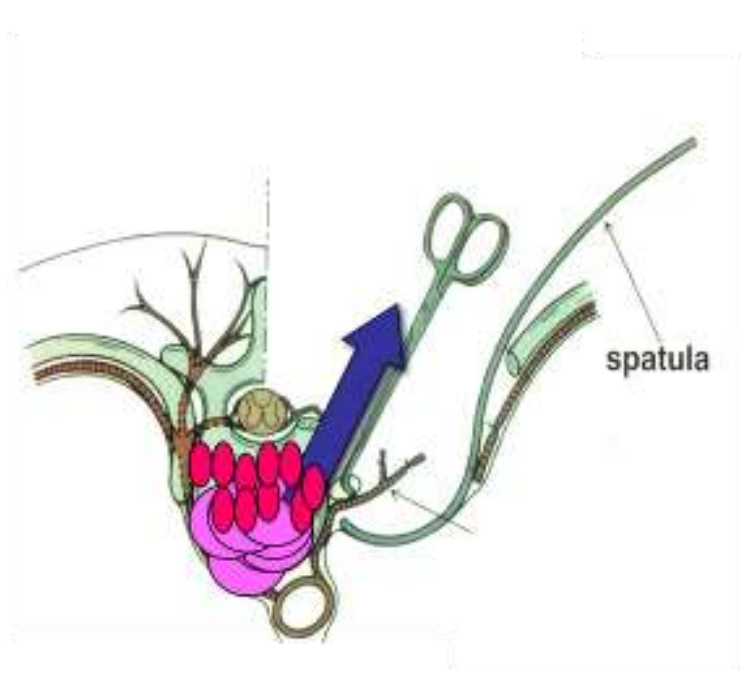

(D)

Figure (1 C, D): Circum- spinal dissection was performed and currettage of the infected material. 


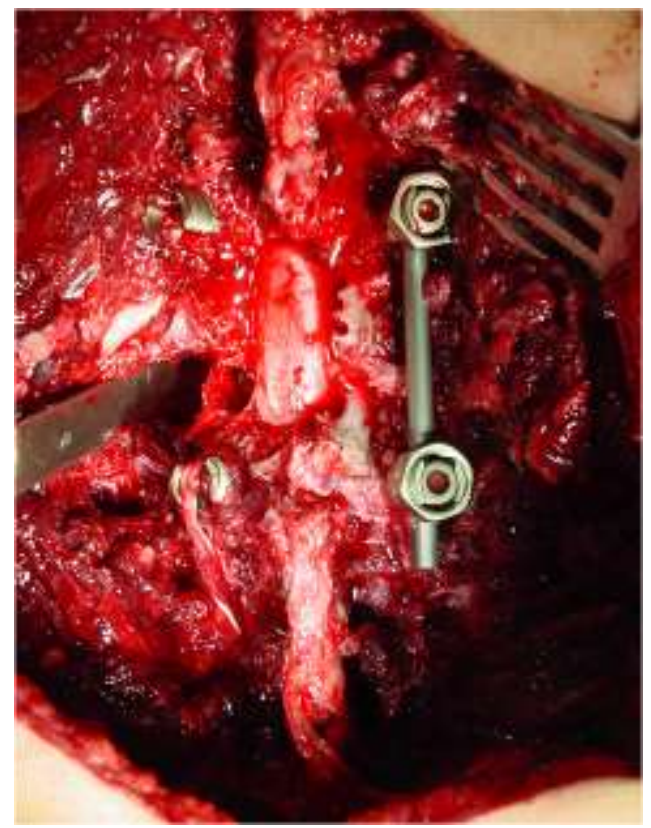

Figure (1 E): Circumspinal dissection with the apatual inserted to protect the pleura and give space of curretage of the infected disc.

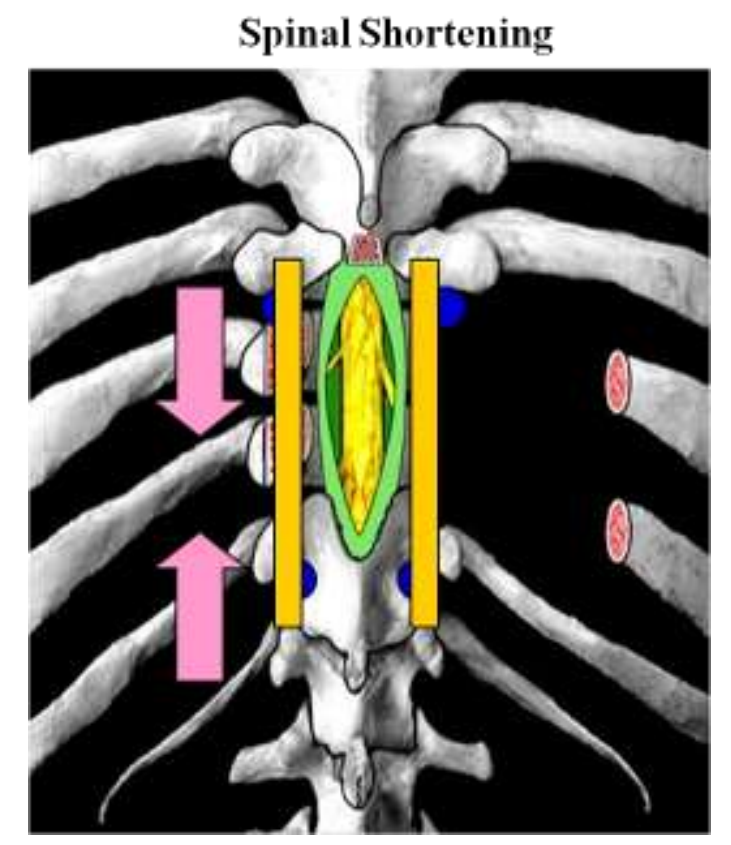

Figure (1 F): Shortening is performed. 


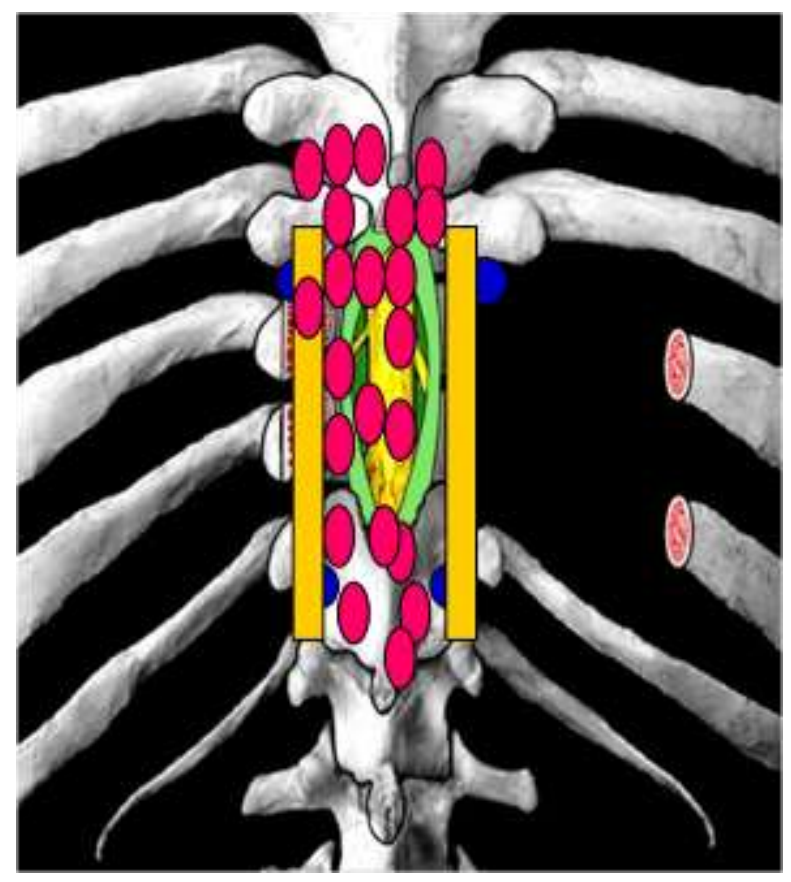

Figure (1 G): Posterior fusion.

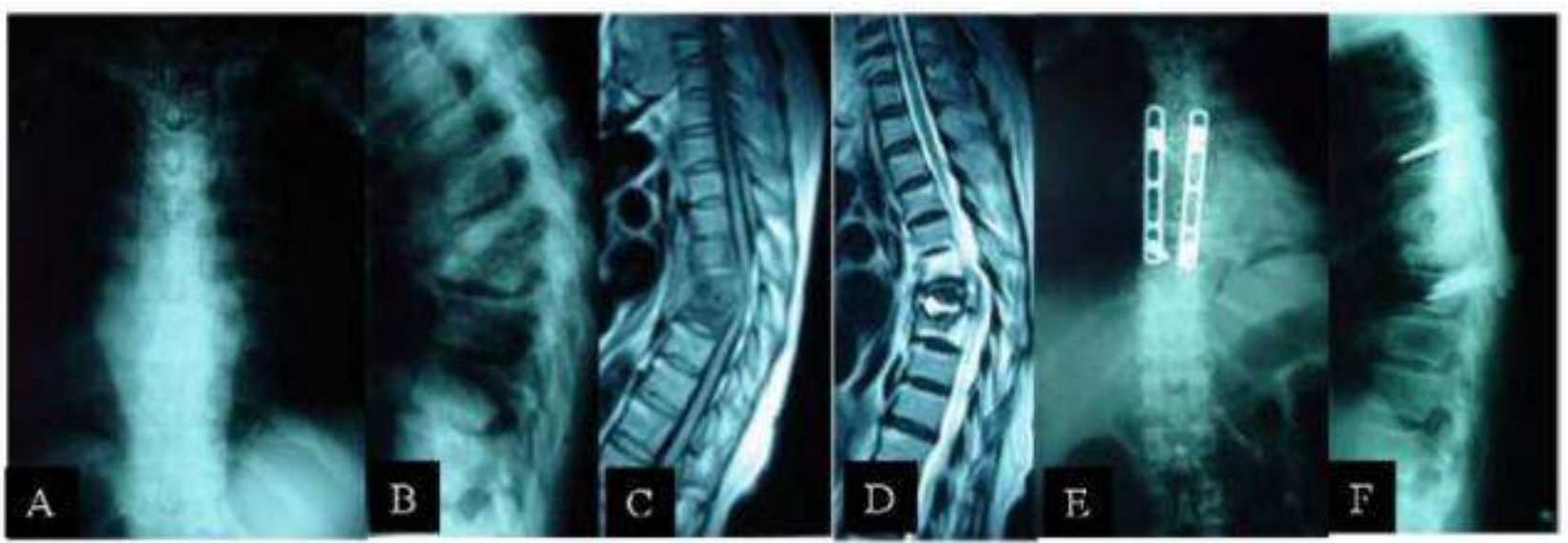

Figure (2): Patient 2: female patient 65 years old presented with paraplegia (Frankel grade B) A and B:AP and lateral plain radiographs showing severe collapse Th 6-8 with affection of the intervertabral disc spaces and severe collapse. C: MRI sagittal T1-weighted image and D: MRI sagittal T2 -weighted image showing severe destruction with abscess formation and compression on the spinal cord. E and F: Post-operative plain radiographs showing correction of the pre-operative kyphosis. The medial few centimeters on the left $6^{\text {th }}$ and $7^{\text {th }}$ ribs were excised to achieve the circumspinal exposure. 


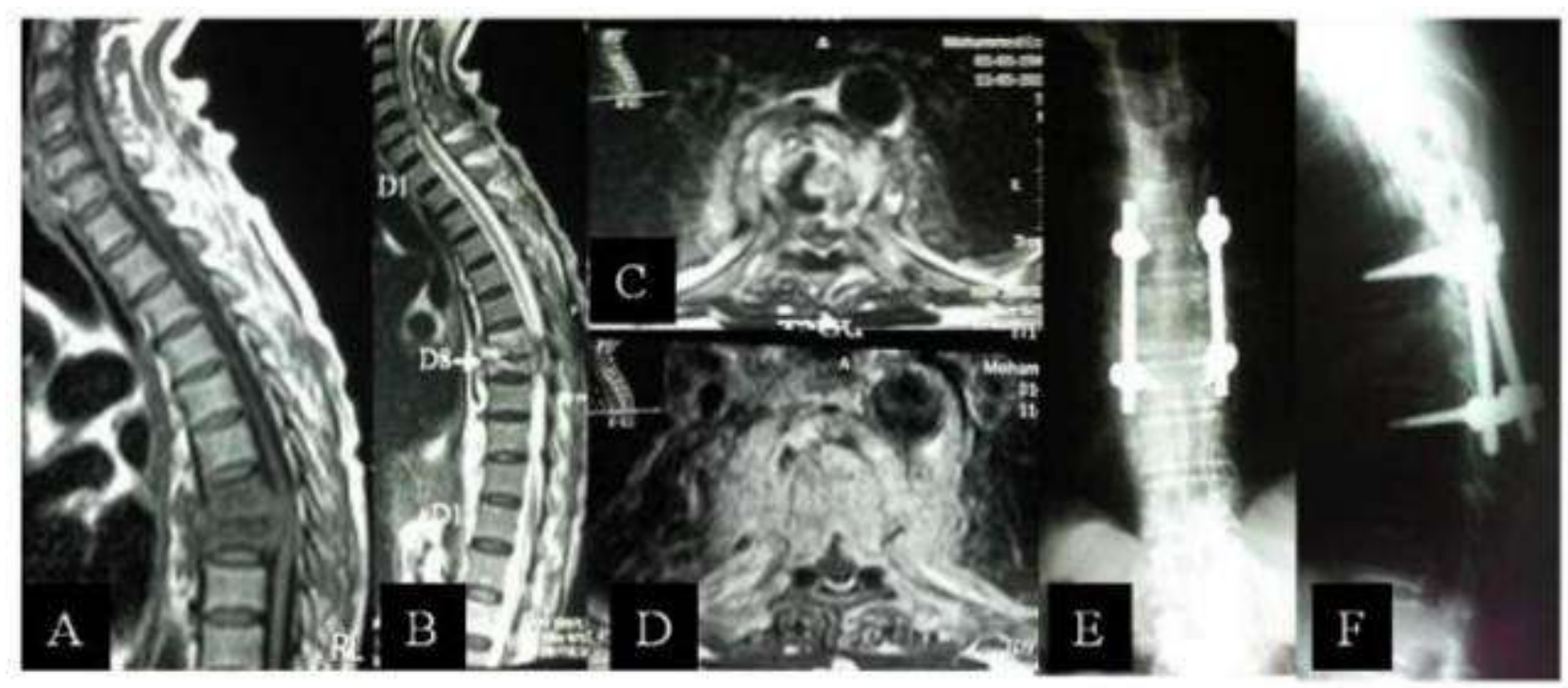

Figure (3): Patient 9: male patient 50 years old presented with spasticity of both lower limbs paraplegia although the motor power of muscles of lower limbs 5. A: MRI sagittal T1-weighted image and B: MRI sagittal T2-weighted image showing severe destruction with abscess formation and compression on the spinal cord at the level of Th7-8. C: MRI axial T2weighted image at the level of Th7-8 disc and D: MRI gadolinium enhanced axial image at the level of Th7-8 disc showing big paraspinal abscess and spinal cord compression. E and F: Post-operative plain radiographs showing instrumentation to the pedicles of Th 6 and 9 vertebrae with anterior the lower border of Th7 comes to contact to the upper border of Th8.
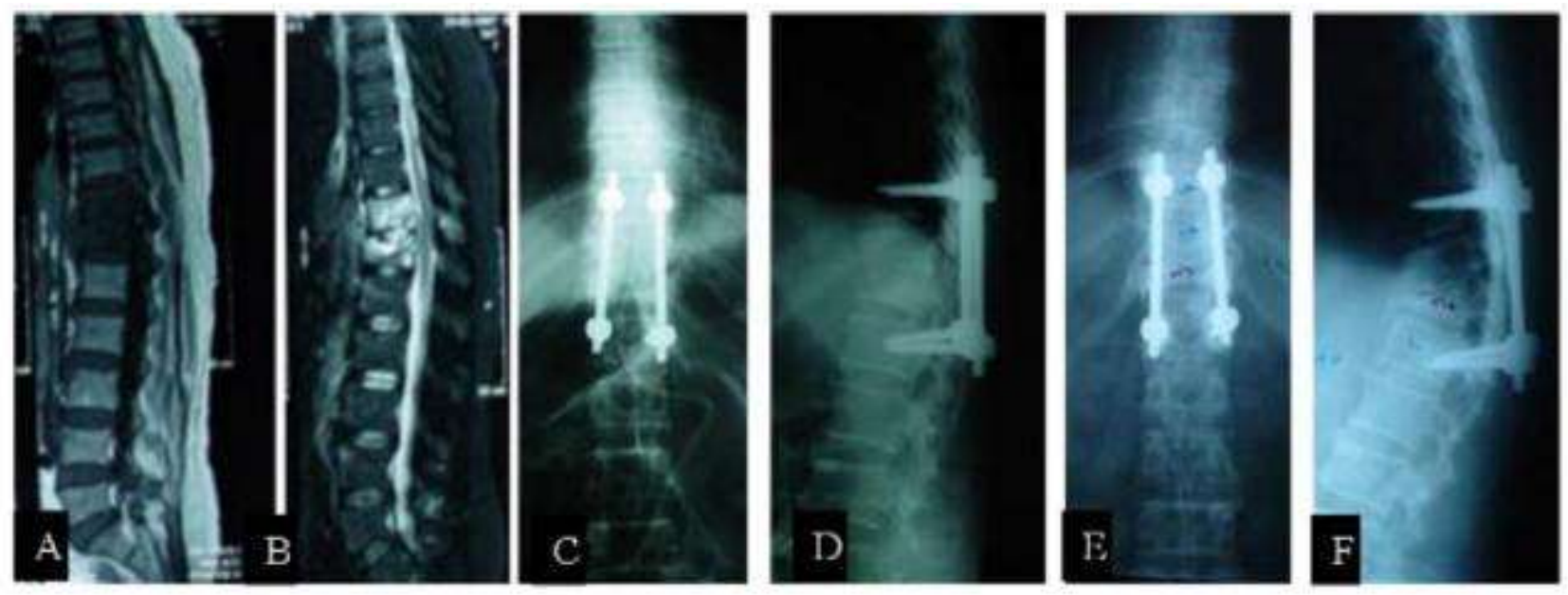

Figure (4): Patient 3: female patient 60 years old presented with mid-back pain (Frankel grade E) A: MRI sagittal T1weighted limage and B: MRI sagittal T2-weighted image showing destruction with abscess formation at the level of Th1112. C and D: Post-operative plain radiographs showing insertion of pedicle screws into Th 10 and L1 and anterior reconstruction by spinal shortening. E and F: Plain radiographs 16 months post-operative with fusion successfully achieved but in a kyphotic position. However, the patient was satisfied with the result and no further intervention was needed. 


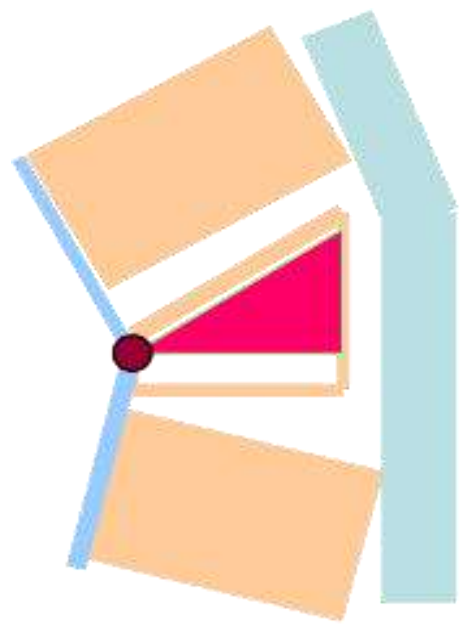

Before Shortening

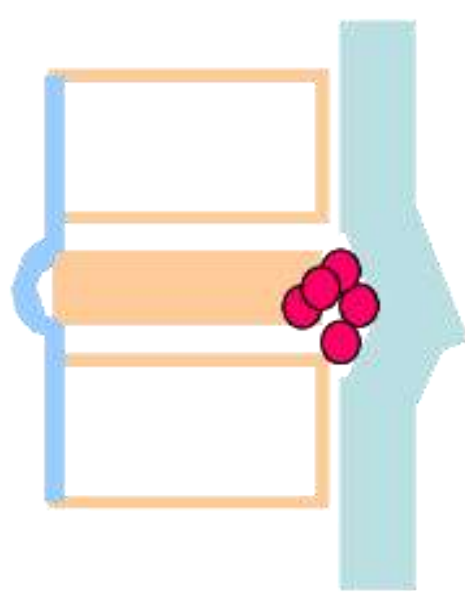

After Shortening

Figure (5): After achievement of full shortening, the surgeon must check the anterior aspect of the spinal cord, as shortening may result in pushing of debris into the spinal cord that may cause spinal cord compression.

\section{DISCUSSION}

In our opinion, single posterolateral exposure can be used to stabilize the spine through transpedicular instrumentation, debride the anterior focus of infection, and anterior reconstruction of the spine can be achieved by limited spinal shortening. We successfully used this technique in treatment of 10 patients of infections of the thoracic spine.

The basic goals of management of spinal infections are eradication of infection, prevention or reversal of neurological deficit, and relief of pain ${ }^{(15)}$. When surgery is indicated, anterior debridment and fusion by using autografts is an accepted way of treatment ${ }^{(3,4,8}$, 9). However, in last few years a shift occurred in the preferred surgical approach for management of thoracic spinal infections with a lot of research works reported better results with posterior surgical approach ${ }^{(1-3,6,7,16)}$. There are few papers that should be considered an addition in this point because they compared between the single posterior approach versus combined anterior and posterior surgeries. El-Sharkawi and Said ${ }^{(6)}$ compared the results of one stage circumferential fusion and anterior debridement and fusion followed 10-14 days later by posterior stabilization and posterolateral fusion for treatment of dorsolumbar spine tuberculosis. They reported that one-stage surgery is advantageous because it has a lower complication rate, shorter hospital stay, less operative time and blood loss.

Zhang et al. ${ }^{(16)}$ retrospectively reviewed 36 cases of thoracic spinal tuberculosis treated by two different surgical procedures: 20 cases in Group A underwent single-stage posterior debridement, transforaminal fusion and instrumentation, and 16 cases in Group B underwent posterior instrumentation, anterior debridement and bone graft in a single- or two-stage procedure. They concluded that the posterior approach only procedure obtained better clinical outcomes than combined posterior and anterior surgeries. They considered that single-stage posterior debridement is a better surgical treatment for thoracic spinal tuberculosis in aged patients with poor health status, especially for cases in early phase of bone destruction and/or mild and moderate kyphosis. A meta analysis published in 2016 by Yang et al proved that posterior approach has better clinical outcomes than anterior or combined approach for spinal tuberculosis ${ }^{(\mathbf{1 7})}$.

In our opinion and based in our experience in management of our patients, the posterolateral exposure of the spine used as a sole approach has a lot of advantages over the anterioror combined posterior/anterior exposure in treatment of infections of the thoracic vertebrae. It carries less morbidity, spine surgeons are more familiar with the posterior exposure than the anterior one, it gives access to both the vertebral body and neural arch and for multiple levels, it gives access to all levels from Th 1 to Th 12 and complications are less serious. Another main advantage of posterior spinal exposure is that the spinal cord is always under surgeon's vision during debridement and reconstruction. This is contrary to the situation in case of anterior spinal debridement because the spinal cord lies behind the vertebral body. If dural tear to complicate anterior debridement, dural reconstruction through the anterior exposure is extremely difficult. Further- in our technique- reconstruction of the anterior column could be achieved by limited spinal shortening, so that avoiding the complications of bone graft harvesting and insertion. The operative time is short, and spinal fixation allowed early mobilization. Spinal shortening was reported in the literature for treatment of several surgical indications including fractures, deformities, tethered cord and tumors $(\mathbf{1 0}, \mathbf{1 2}, \mathbf{1 8 )}$. However, it was only reported in treatment of spinal infections in 2 research works one of them by the senior author of the current manuscript in $2006^{(\mathbf{1}, \mathbf{2}, \mathbf{4 , 1 9})}$.

Two Patients (No. 1 and 2) of the current study were included in our first report in 2006 but with longer follow up. Later on, Chanplakorn et al. ${ }^{(4)}$ reported 3 patients of tuberculous spondylitis in the thoracic spine treated by spinal shortening. Spinal shortening has a lot of advantages; decreases the need for bone graft, shorten the 
operative time, give wide cancellous surface areas for bony healing, avoid the possible complication of graft dislodgment and avoid the complications of bone grafting operation. However, the limits of spinal shortening must be taken into consideration specially when dealing with the spinal cord in the thoracic spine. Experimental work in a canine model to detect the safe limits of spinal shortening in the thoracic spine area showed that during acute spinal shortening the spinal cord and dura pass through 3 phases: safety range: occurred during shortening within one-third of the vertebral segment and is characterized by no deformity of the dural sac neither the spinal cord, warning range: occurs during spinal shortening between one and two-thirds of the vertebral segment and is characterized by shrinking and buckling of the dural sac and no deformity of the spinal cord and critical range: occurred after shortening in excess of twothirds of the vertebral segment and is characterized by spinal cord deformity and compression by the buckled dura. In this phase, spinal evoked potential changes could be detected ${ }^{(\mathbf{1 1 )}}$. A recent study by Lu et al. ${ }^{(20)}$ explored the effect of spinal shortening on blood flow and function of the spinal cord during spinal cord angulation. The study concluded that; when the spinal cord is shortened by $1 / 4$ to $2 / 4$ of a vertebral height, the tolerance of the spinal cord can increase and spinal cord injury resulting from angulation can be avoided. However, when the shortening reaches $3 / 4$ or a full length of vertebral height, it is harmful to the spinal cord. In all of our patients, we did not exceed the safe limit of spinal shortening. According to our experience, the danger of neurological compromise might occur as a result of anterior compression of the spinal cord by any bone fragment or debris pushed into the spinal canal during spinal shortening. For that, we insist to check the anterior aspect of the cord after achieving full shortening to be sure that there is no anterior compression to the cord (Figure 5).

\section{CONCLUSION}

It could be concluded that in cases of thoracic spinal infections, single posterolateral exposure is sufficient to debride the infected material, decompress the neural elements, and reconstruct the spine. Limited spinal shortening allows anterior reconstruction without the need for bone grafting.

\section{REFERENCES}

1. Arnold P, Baek P, Bernardi $R$ et al. (1997): Surgical management of nontuberculous thoracic and lumbar vertebral osteomyelitis: report of 33 cases. Surg Neurol., 47:551-8.

2. Singh K, Heller J (2005): Postoperative spinal infections. Contemp Spine Surg., 6(9):61-68.

3. American Association of Neurological Surgeons (2016): Spinal https://www.aans.org/en/Patients/NeurosurgicalConditions-and-Treatments/Spinal-Infections. Published May 2016. Accessed December 29, 2016.
4. Chanplakorn $\mathrm{P}$, Chanplakorn $\mathrm{N}$, Kraiwattanapong $\mathrm{C}$ et al. (2011): Treatment of Acute Tuberculous Spondylitis by the Spinal Shortening Osteotomy: A Technical Notes and Case Illustrations. Asian Spine J., 5(4): 237-244.

5. Dai L, Jiang L, Wang W et al. (2005): Single-stage anterior autogenous bone grafting and instrumentation in the surgical management of spinal tuberculosis. Spine, 30(20): 2342-2349.

6. El-Sharkawi M, Said G (2011): Instrumented circumferential fusion for tuberculosis of the dorso-lumbar spine. A single or double stage procedure? Int Orthop., 36: 315-324, 2011.

7. Guzey F, Emel E, Bas $\mathbf{N}$ et al. (2005): Thoracic and lumbar tuberculous spondylitis treated by posterior debridement, graft placement, and instrumentation: a retrospective analysis in 19 cases. J Neurosurg Spine, 3 (6):450-458.

8. Korovessis P, Petsinis G, Koureas G et al. (2006): Anterior surgery with insertion of titanium mesh cage and posterior instrumented fusion performed sequentially on the same day under one anesthesia for septic spondylitis of thoracolumbar spine: is the use of titanium mesh cages safe? Spine, 31(9):1014-1019.

9. Krodel A, Kruger K, Loscheidt M et al. (1999): Anterior debridment, fusion and extrafocal stabilization in the treatment of osteomyelitis of the spine. J Spinal Disord., 12:17-26.

10. Saita K, Hoshino Y, Kikkawa I et al. (2000): Posterior Spinal Shortening for Paraplegia After Vertebral Collapse Caused by Osteoporosis. Spine, 25 (21): 2832-2835.

11. Kawahara N, Tomita K, Kobayashi $T$ et al. (2005): Influence of Acute Shortening on the Spinal Cord: An Experimental Study. Spine, 30 (6): 613-620.

12. Murakami H, Kawahara $\mathrm{N}$, Abdel-Wanis $M$ et al. (2001): Total En Bloc Spondylectomy. Semin Musculoskelet Radiol., 5: 189-194.

13. Tomita K, Kawahara N, Baba H et al. (1997): Total en bloc spondylectomy- a new surgical technique for primary malignant vertebral tumors. Spine, 22 (3): 324-333.

14. Tay B, Deckey J, Hu S (2002): Spinal Infections. J Am Acad Orthop Surg., 10:188-197.

15. Mackenzie A, Laing $R$, Smith $C$ et al. (1998): Spinal epidural abscess: the importance of early diagnosis and treatment. J Neurol Neurosurg Psychiatry, 65:209-212.

16. Zhang H, Li J, Zhao S et al. (2012): Surgical management for thoracic spinal tuberculosis in the elderly: posterior only versus combined posterior and anterior approaches. Arch Orthop Trauma Surg., 132(12):1717-23.

17. Yang $\mathbf{P}$, Zang Q, Kang $\mathbf{J}$ et al. (2016): Comparison of clinical efficacy and safety among three surgical approaches for the treatment of spinal tuberculosis: a metaanalysis Eur Spine J., 25:3862-3874.

18. Bradford D, Clifford B (1997): Vertebral column resection for the treatment of rigid coronal decompression. Spine, 22: 1590-1599.

19. Abdel-Wanis M (2013): Surgical Treatment of Lumbar Spine Infections by Posterior Lumbar Interbody Fusion with Anterior Reconstruction by Spinal Shortening. The Pan Arab Journal of Orthopaedics and Trauma, 17(1): 1-8.

20. Lu Q, Wang Y, Xie J et al. (2019): Effect of Spinal Shortening for Protection of Spinal Cord Function in Canines with Spinal Cord Angulation. Med Sci Monit., 25:9192-9199. 